\title{
Simulation of Spontaneous Secondary Hyperaldosteronism by Intravenous Infusion of Angiotensin II in Dogs with an Arteriovenous Fistula *
}

\author{
John Urquhart, James O. Davis, and James T. Higgins, JR., With the tech- \\ nical assistance of Eleanor Cavanaugh and Charles Pearson \\ (From the Section on Experimental Cardiovascular Disease, Laboratory of Kidney and \\ Electrolyte Metabolism, National Heart Institute, Bethesda, Md.)
}

\begin{abstract}
Although a large body of evidence indicates that the renin-angiotensin system mediates the renal control of aldosterone secretion, there is little information pertinent to the question of whether renin or angiotensin II mimics the effects of aldosterone on water and electrolyte metabolism. In view of the well-documented stimulatory action of angiotensin II on aldosterone secretion (2), the effects of the octapeptide on electrolyte metabolism should correspond with those of aldosterone unless there are extraadrenal actions of angiotensin II that override the effects of aldosterone. There is evidence, for example, that under certain circumstances angiotensin II inhibits the renal tubular reabsorption of sodium $(3,4)$. In our present study, the effects of prolonged infusion of angiotensin II were examined in dogs with a large arteriovenous (a-v) fistula and were compared with the effects of desoxycorticosterone acetate (DCA) and of aldosterone. Angiotensin II was also infused into adrenalectomized dogs with an a-v fistula during maintenance with small amounts of adrenocortical steroids.
\end{abstract}

Dogs with a large arteriovenous fistula do not manifest the normally occurring "escape" from the sodium-retaining action of exogenous electrolyte-active steroids (5); otherwise, electrolyte metabolism appears to be normal, and the animals maintain sodium balance in the often long interval between fistula placement and the onset of congestive heart failure. During prolonged mineralocorticoid treatment, dogs with an a-v fistula but without cardiac failure continue to retain sodium virtually completely, whereas nor-

* Submitted for publication November 18, 1963; accepted February 24, 1964.

A preliminary report has appeared (1). mal dogs regain sodium balance after only 1 to 2 days of frequently incomplete sodium retention (6). In normal dogs, angiotensin II also produces only transient sodium retention (7). In dogs with an a-v fistula, however, the effects of angiotensin II that are attributable to aldosterone should be clearly evident and should not be obscured by the renal escape phenomenon.

The onset of heart failure in dogs with an a-v fistula is marked by the development of hypersecretion of aldosterone, sodium retention, and central venous congestion (8). The increased secretion of aldosterone is effected by the kidneys, apparently through the renin-angiotensin system, as in other states of spontaneous secondary hyperaldosteronism. If the conclusion is correct that it is increased renin release and thus enhanced angiotensin II formation that induces hypersecretion of aldosterone and consequent sodium retention, then the administration of angiotensin II to dogs with an a-v fistula but without cardiac failure should produce the changes in electrolyte metabolism characteristic of spontaneous secondary hyperaldosteronism.

\section{Methods}

Eleven female mongrel dogs weighing 18 to $22 \mathrm{~kg}$ underwent placement of a $12-$ to $15-\mathrm{mm}$, side-to-side, infrarenal, aortic-inferior, vena caval anastomosis 14 days or more before study. The dogs were kept in metabolic cages and were fed a standard synthetic diet supplying $60 \mathrm{mEq}$ of sodium and $18 \mathrm{mEq}$ of potassium per day.

Valine-5-angiotensin II 1 or $d$-aldosterone in saline was infused intravenously through an indwelling femoral venous catheter, which had been inserted percutaneously using a thin-wall needle. A Rose osmotically driven infusion pump (9) provided an average infusion rate of $1 \frac{1}{2} \mathrm{ml}$ per 24 hours and was constant to within

1 Hypertensin, Ciba Pharmaceuticals, Summit, N. J. 
TABLE I

Effects of angiotensin II in dogs with an arteriovenous fistula

\begin{tabular}{|c|c|c|c|c|c|c|c|c|c|c|}
\hline \multirow[b]{3}{*}{ Date } & \multirow{3}{*}{$\begin{array}{c}\text { Angio- } \\
\text { tensin } \\
\text { II }\end{array}$} & \multicolumn{4}{|c|}{ Electrolyte excretion } & \multirow{3}{*}{$\begin{array}{l}\text { Fecal } \\
\mathrm{Na} / \mathrm{K}\end{array}$} & \multirow{3}{*}{$\begin{array}{l}\text { Plasma } \\
\text { Na }\end{array}$} & \multirow{3}{*}{$\underset{\mathbf{K}}{\text { Plasma }}$} & \multirow{3}{*}{$\begin{array}{c}\text { Mean } \\
\text { arterial } \\
\text { pressure }\end{array}$} & \multirow{3}{*}{$\begin{array}{l}\text { External } \\
\text { jugular } \\
\text { venous } \\
\text { pressure }\end{array}$} \\
\hline & & \multicolumn{2}{|c|}{$\mathrm{Na}$} & \multicolumn{2}{|c|}{$\mathrm{k}$} & & & & & \\
\hline & & Urine & Feces & Urine & Feces & & & & & \\
\hline A. Dogs with & $\begin{array}{l}\mu g / \mathrm{kg} / \mathrm{day} \\
\text { renals intact }\end{array}$ & \multicolumn{2}{|c|}{$m E q / d a y$} & \multicolumn{2}{|c|}{$m E q / d a y$} & & $m E q / L$ & $m E q / L$ & $m m \mathrm{Hg}$ & $m m$ water \\
\hline $\begin{array}{r}9 / 6-9 / 10 \\
9 / 11-9 / 17 \\
9 / 18-9 / 22\end{array}$ & $\begin{array}{r}0 \\
47 \\
0\end{array}$ & $\begin{array}{l}34 \\
13 \\
58\end{array}$ & $\begin{array}{l}3.0 \\
1.9 \\
3.0\end{array}$ & $\begin{array}{l}18 \\
12 \\
12\end{array}$ & $\begin{array}{l}\text { Dog } 1 \\
0.7 \\
2.5 \\
0.5\end{array}$ & $\begin{array}{l}4.3 \\
0.8 \\
6.0\end{array}$ & $\begin{array}{l}146 \\
149 \\
145\end{array}$ & $\begin{array}{l}4.5 \\
4.1 \\
4.4\end{array}$ & $\begin{array}{l}110 \\
117 \\
106\end{array}$ & $\begin{array}{l}85 \\
87 \\
86\end{array}$ \\
\hline $\begin{array}{c}9 / 1-9 / 5 \\
9 / 6-9 / 16 \\
9 / 17-9 / 21\end{array}$ & $\begin{array}{r}\mathbf{0} \\
\mathbf{3 0} \\
\mathbf{0}\end{array}$ & $\begin{array}{r}48 \\
5 \\
89\end{array}$ & $\begin{array}{l}2.9 \\
2.6 \\
4.3\end{array}$ & $\begin{array}{l}20 \\
17 \\
20\end{array}$ & $\begin{array}{c}\text { Dog } 2 \\
0.8 \\
1.3 \\
1.8\end{array}$ & $\begin{array}{l}3.6 \\
2.0 \\
2.4\end{array}$ & $\begin{array}{l}146 \\
143 \\
144\end{array}$ & $\begin{array}{l}4.5 \\
4.6 \\
4.2\end{array}$ & $\begin{array}{l}100 \\
121 \\
111\end{array}$ & $\begin{array}{l}68 \\
99 \\
91\end{array}$ \\
\hline $\begin{array}{c}11 / 20-11 / 24 \\
11 / 25-12 / 1 \\
12 / 2-12 / 6\end{array}$ & $\begin{array}{r}\mathbf{0} \\
\mathbf{4 0} \\
\mathbf{0}\end{array}$ & $\begin{array}{r}35 \\
5 \\
107\end{array}$ & $\begin{array}{l}4.5 \\
1.3 \\
4.0\end{array}$ & $\begin{array}{l}16 \\
18 \\
18\end{array}$ & $\begin{array}{c}\text { Dog } 3 \\
0.7 \\
5.3 \\
1.1\end{array}$ & $\begin{array}{l}6.4 \\
0.3 \\
3.6\end{array}$ & $\begin{array}{l}144 \\
144 \\
144\end{array}$ & $\begin{array}{l}4.3 \\
4.1 \\
4.3\end{array}$ & $\begin{array}{l}128 \\
136 \\
138\end{array}$ & $\begin{array}{l}114 \\
119 * \\
106\end{array}$ \\
\hline $\begin{array}{l}11 / 29-12 / 3 \\
12 / 4-12 / 10 \\
12 / 11-12 / 15\end{array}$ & $\begin{array}{r}0 \\
47 \\
0\end{array}$ & $\begin{array}{r}42 \\
5 \\
56\end{array}$ & $\begin{array}{l}2.2 \\
1.3 \\
2.3\end{array}$ & $\begin{array}{l}21 \\
17 \\
20\end{array}$ & $\begin{array}{c}\text { Dog } 4 \\
0.4 \\
3.5 \\
0.5\end{array}$ & $\begin{array}{l}5.5 \\
0.4 \\
4.6\end{array}$ & $\begin{array}{l}146 \\
142 \\
142\end{array}$ & $\begin{array}{l}4.3 \\
4.1 \\
4.0\end{array}$ & $\begin{array}{l}73 \\
72 \\
75\end{array}$ & $\begin{array}{l}113 \\
122 \\
127\end{array}$ \\
\hline \multicolumn{11}{|c|}{ B. Adrenalectomized dogs } \\
\hline $\begin{array}{c}10 / 29-11 / 2 \\
11 / 3-11 / 8 \\
11 / 9-11 / 13\end{array}$ & $\begin{array}{c}0 \\
47 \\
0\end{array}$ & $\begin{array}{l}53.4 \\
30.0 \\
29.0\end{array}$ & $\begin{array}{l}5.5 \\
2.9 \\
5.4\end{array}$ & $\begin{array}{l}17.9 \\
26.6 \\
18.8\end{array}$ & $\begin{array}{c}\text { Dog } 1 \\
1.1 \\
0.6 \\
1.2\end{array}$ & $\begin{array}{l}5.0 \\
4.8 \\
4.5\end{array}$ & $\begin{array}{l}145 \\
137 \\
140\end{array}$ & $\begin{array}{l}5.2 \\
5.0 \\
4.6\end{array}$ & $\begin{array}{l}88 \\
81\end{array}$ & $\begin{array}{l}73 \\
80\end{array}$ \\
\hline $\begin{array}{c}10 / 21-10 / 24 \\
10 / 25-10 / 31 \\
11 / 1-11 / 5\end{array}$ & $\begin{array}{r}0 \\
43 \\
0\end{array}$ & $\begin{array}{l}55.0 \\
40.3 \\
26.8\end{array}$ & $\begin{array}{l}4.6 \\
2.4 \\
2.8\end{array}$ & $\begin{array}{l}10.7 \\
15.9 \\
13.8\end{array}$ & $\begin{array}{c}\text { Dog } 2 \\
1.1 \\
0.7 \\
0.8\end{array}$ & $\begin{array}{l}4.2 \\
3.4 \\
3.5\end{array}$ & $\begin{array}{l}143 \\
141 \\
140\end{array}$ & $\begin{array}{l}4.7 \\
5.0 \\
4.9\end{array}$ & $\begin{array}{r}98 \\
115 \\
104\end{array}$ & $\begin{array}{l}85 \\
79 \\
67\end{array}$ \\
\hline $\begin{array}{l}1 / 31-2 / 3 \\
2 / 4-2 / 9 \\
2 / 10-2 / 14\end{array}$ & $\begin{array}{r}0 \\
34 \\
0\end{array}$ & $\begin{array}{l}46.6 \\
38.9 \\
25.8\end{array}$ & $\begin{array}{l}5.0 \\
1.7 \\
2.7\end{array}$ & $\begin{array}{l}11.3 \\
17.8 \\
13.5\end{array}$ & $\begin{array}{c}\text { Dog } 3 \\
0.7 \\
0.1 \\
0.6\end{array}$ & $\begin{array}{r}7.1 \\
17.0 \\
4.5\end{array}$ & $\begin{array}{l}144 \\
141 \\
140\end{array}$ & $\begin{array}{l}3.9 \\
4.9 \\
4.5\end{array}$ & $\begin{array}{l}105 \\
102 \\
121\end{array}$ & $\begin{array}{l}122 \\
106 \\
110\end{array}$ \\
\hline
\end{tabular}

* Does not include the values on the last 2 days of infusion; see text.

approximately $20 \%$, with one exception that is discussed below. The average dose of angiotensin II varied from 30 to $47 \mu \mathrm{g}$ per $\mathrm{kg}$ per day. The details of this technique for prolonged intravenous infusion have been reported previously (7). In most experiments, saline alone was infused for 24 to 48 hours before the beginning of angiotensin or aldosterone infusion.

Aldosterone and corticosterone were measured by the double isotope derivative technique of Kliman and Peterson (10). Adrenal venous blood was collected through an indwelling adrenolumbar venous catheter, after the technique of Hume and Nelson (11). The values for adrenocortical hormone secretion rates were calculated as the product of the concentration of hormone in adrenal venous plasma and the rate of flow of plasma from one gland.

Sodium and potassium in fecal extracts, urine, and plasma were determined by flame photometry; these cations were leached from feces by methods previously described (12). Arterial blood pressure was measured in the femoral artery by direct needle puncture using a Statham strain gauge and a Sanborn recording system. External jugular venous pressure was determined with a water manometer, using the same reference level throughout each experiment.

Adrenalectomized dogs received $12.5 \mathrm{mg}$ of cortisone acetate orally and 0.5 or $0.75 \mathrm{mg}$ of DCA in oil intra- muscularly once daily. One of the two dose levels of DCA proved to be sufficient to achieve approximate sodium balance in each of the adrenalectomized dogs.

The pressor response to single intravenous injections of angiotensin II was determined by a technique reported previously (13).

\section{Results}

Effects of angiotenin II on sodium, water, and potassium metabolism in dogs with an a-v fistula. Both urinary and fecal sodium excretion decreased during angiotensin infusion (Table I-A). Figure 1 presents the results from dog 3 in detail; these findings are representative of the four animals studied. The retention of dietary sodium in $\operatorname{dog} 3$ was almost complete throughout the 7-day infusion, and body weight increased by 2 $\mathrm{kg}$, as pitting edema formed progressively in the hind limbs, perineum, and lower abdominal wall. Ascites was not prominent. After the infusion had ended, a diuresis occurred; within 4 days, the edema disappeared and excess weight was lost. Each of the other three dogs receiving angiotensin 


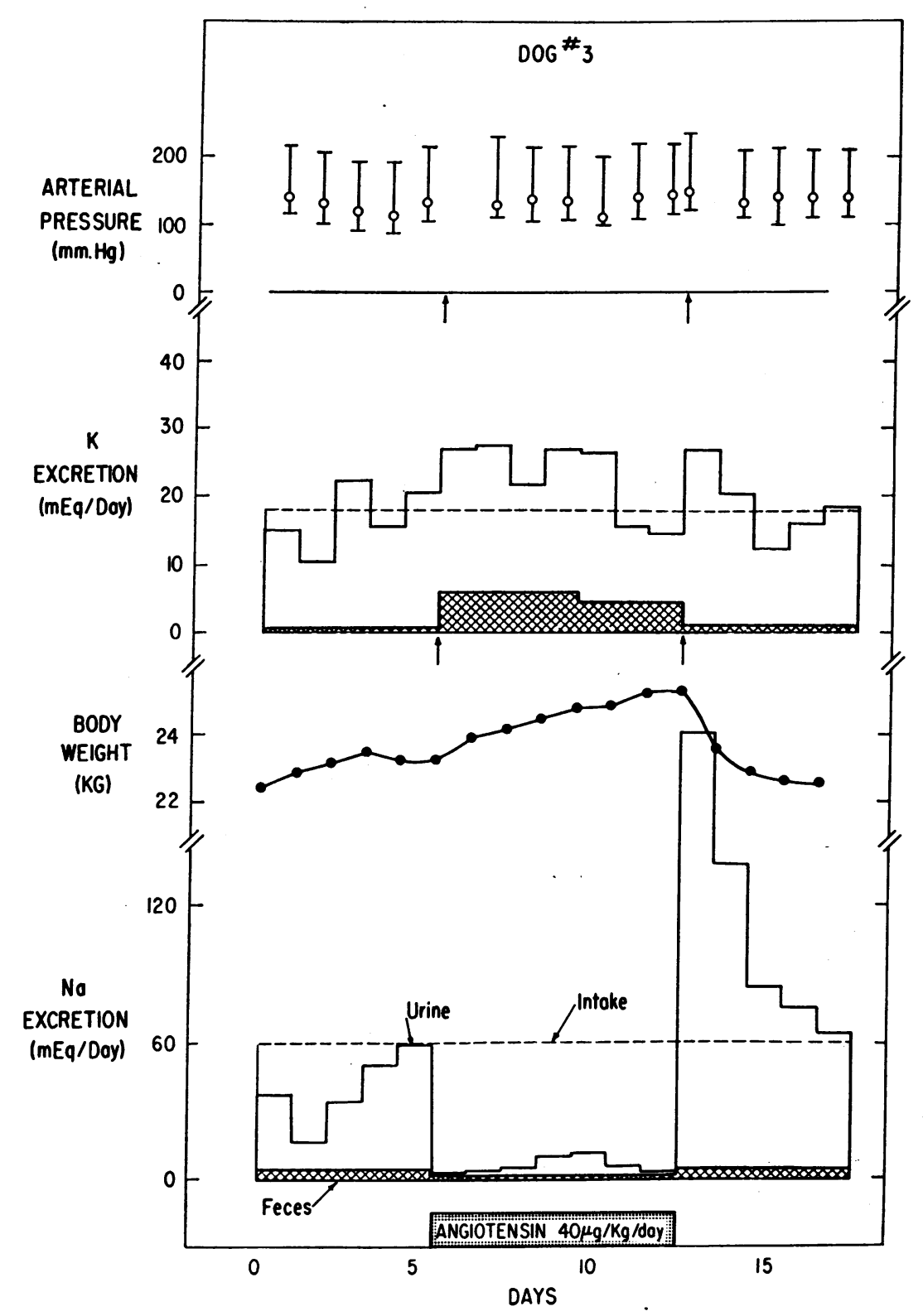

Fig. 1. EFFects OF IV INFUSION OF ANGIOTENSIN II FOR 7 DAYS ON DAILY SODIUM AND POTASSIUM BALANCES, BODY WEIGHT, AND ARTERIAL PRESSURE.

II retained sodium almost completely and formed edema during the infusion period. The least reduction in average sodium excretion was observed in dog 1 (Table I-A), which excreted $50 \mathrm{mEq}$ on the second day of infusion concomitant with an inadvertent $50 \%$ reduction in output by the osmotic pump; on the other 6 days of infusion, urinary sodium excretion ranged between 4.4 and $13.7 \mathrm{mEq}$. After the infusion had been discon- tinued, each of the four dogs underwent a diuresis, with negative sodium balance lasting 1 to 4 days. The upper half of Figure 2 shows the effect of an 11-day infusion of angiotensin on daily urinary sodium excretion in $\operatorname{dog} 2$.

Urine volume was not altered appreciably by angiotensin, but water intake approximately doubled during the infusion in each dog. During the first 1 to 2 days after cessation of infusion, 


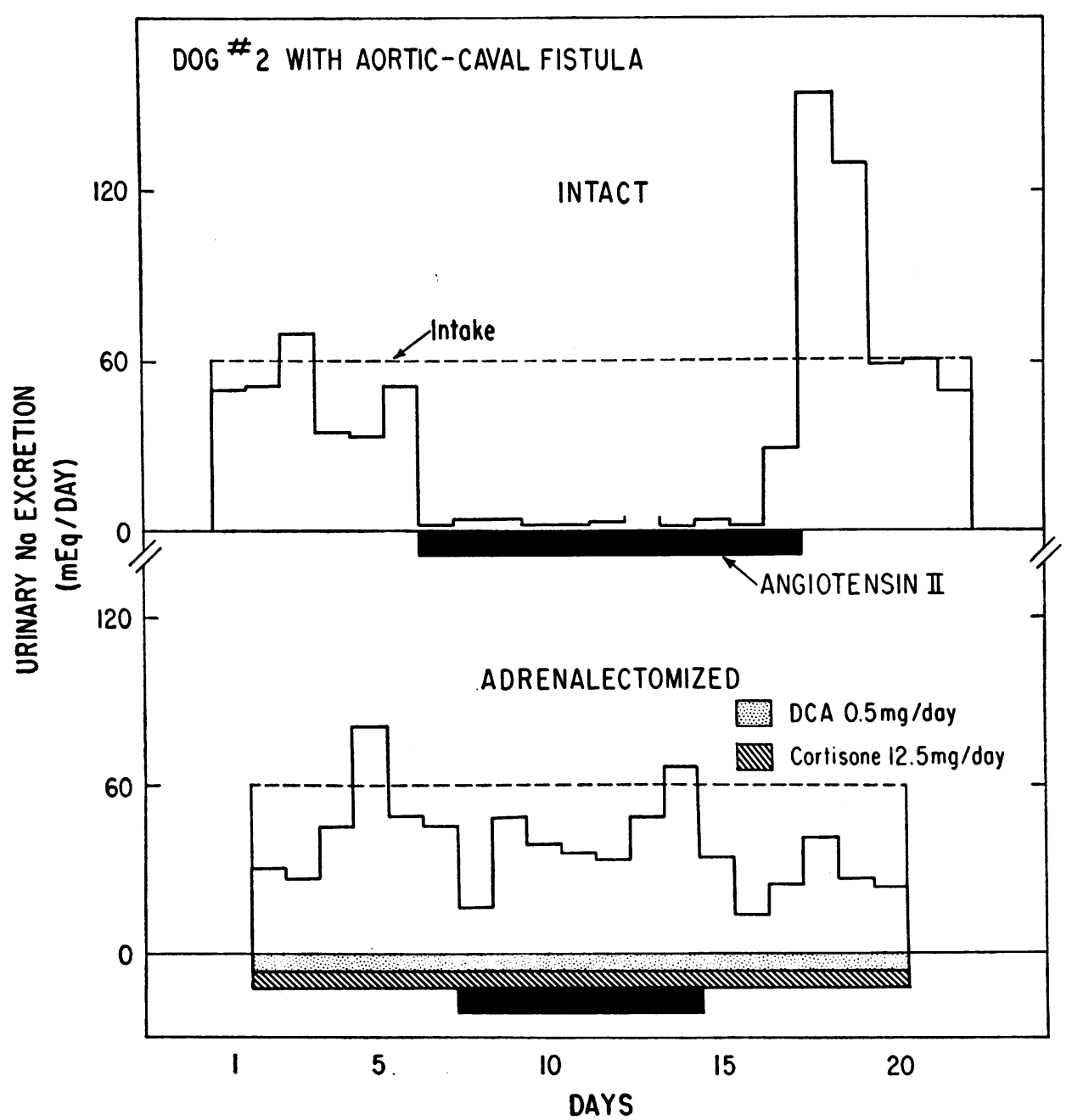

Fig. 2. EFFects OF AN IV INFUSION OF ANGIOTENSIN II ON URINARY SODIUM EXCRETION BEFORE (ABOVE) AND AFTER (BELOW) BILATERAL ADRENALECTOMy. The period of angiotensin infusion is indicated by the solid horizontal bar, and the stippled and shaded horizontal bars designate the administration of desoxycorticosterone acetate (DCA) and cortisone acetate, respectively, in the amounts specified by the key.

water consumption dropped virtually to zero in three of the dogs, while urine volume increased 2- to 4-fold for several days in each animal.

Potassium balance was negative to a slight extent in dog 3 during angiotensin infusion but was unaffected in the other dogs (Table I-A). Angiotensin increased fecal potassium excretion in each animal. This change together with a decline in fecal sodium excretion led to a marked decrease in the fecal sodium/potassium ratio in three of the four dogs (Table I-A). This alteration in fecal electrolyte excretion is characteristic of spontaneous secondary hyperaldosteronism (14) and of treatment with large doses of electrolyteactive steroids (6). Neither plasma sodium nor potassium concentration was affected by angiotensin.

Effects of DCA or aldosterone on sodium, water, and potassium metabolism in dogs with an $a-v$ fistula. For comparison with the effects of angiotensin II, a large daily intramuscular dose of DCA was given to $\operatorname{dog} 2$ (Figure 3 ), and a 5-day intravenous infusion of $d$-aldosterone was given to $\operatorname{dog} 5$ (Figure 4). No qualitative difference was apparent in the responses to the two steroids. Each steroid produced almost complete 


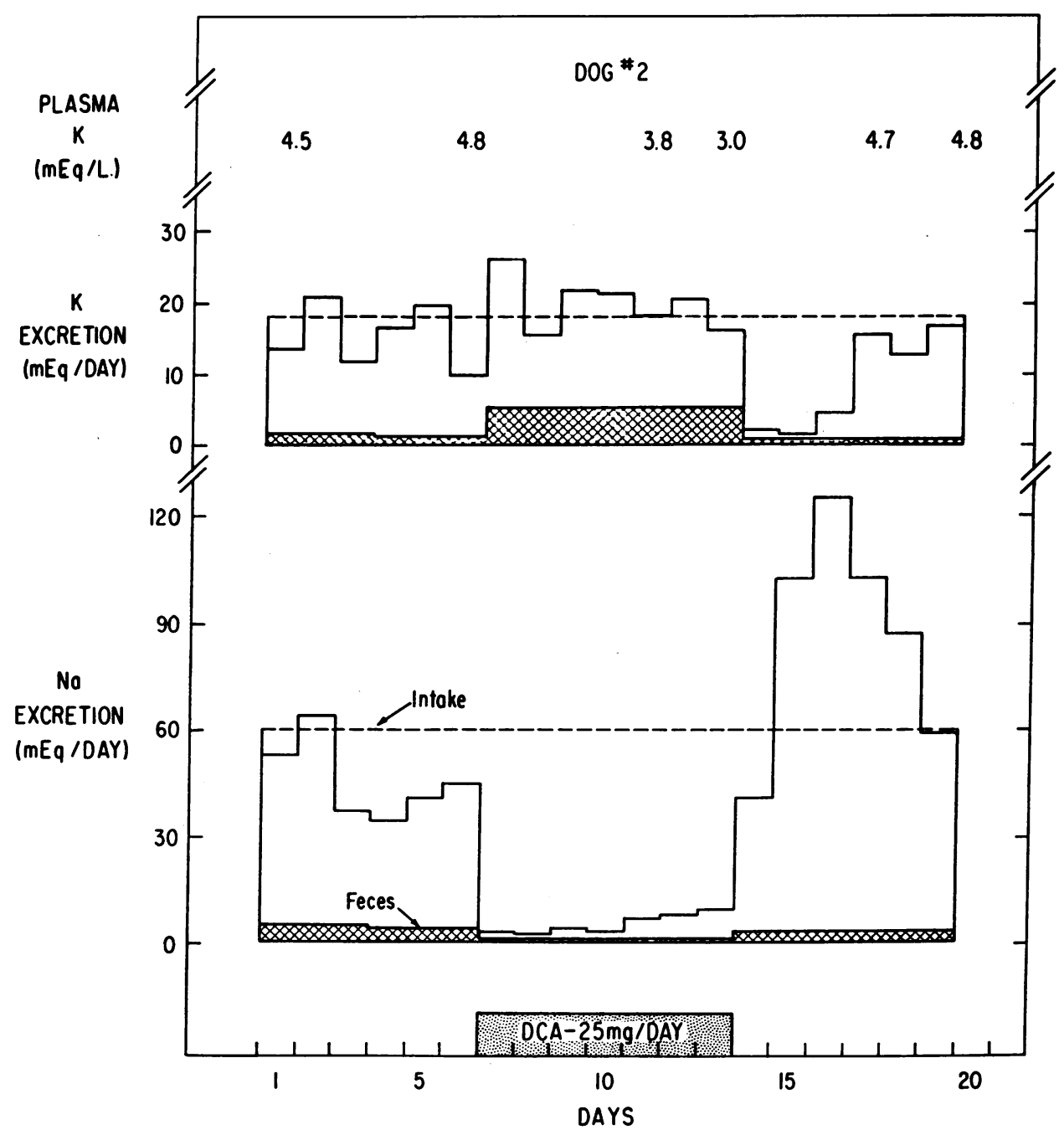

Fig. 3. EfFects of Desoxycorticosterone acetate (25 Mg PER day) ON SOdium ANd POtasSiUM BALANCES AND ON PLASMA POTASSIUM CONCENTRATION.

sodium retention as previously reported (5), decreased fecal sodium excretion, slightly negative potassium balance, increased fecal potassium excretion, and a moderate decline in plasma potassium concentration. Urine volume was unaffected by either steroid. By contrast, in normal animals the electrolyte-active steroids produce transient sodium retention, prolonged kaluresis, rapid development of hypokalemia, and a large increase in water exchange (6).

Effects of angiotensin II on sodium, water, and potassium metabolism in adrenalectomized dogs with an a-v fistula. Three of the four dogs that had received an angiotensin infusion were subsequently bilaterally adrenalectomized and then given maintenance doses of cortisone acetate and DCA. After 4 to 5 days of suitably stable sodium balance with maintenance therapy constant, angiotensin II infusion was repeated. Figure 2 illustrates the contrasting effects of angiotensin on urinary sodium excretion before (upper half) and after (lower half) adrenalectomy in $\operatorname{dog} 2$. Table I-B presents the results in each of the adrenalectomized dogs. In contrast to the unequivocal effect of angiotensin II on urinary sodium excretion in the dogs with intact adrenals, no such action of angiotensin II was discernible in the adrenalectomized animals. Average daily sodium excretion declined somewhat during the infusion period relative to the control period, but 


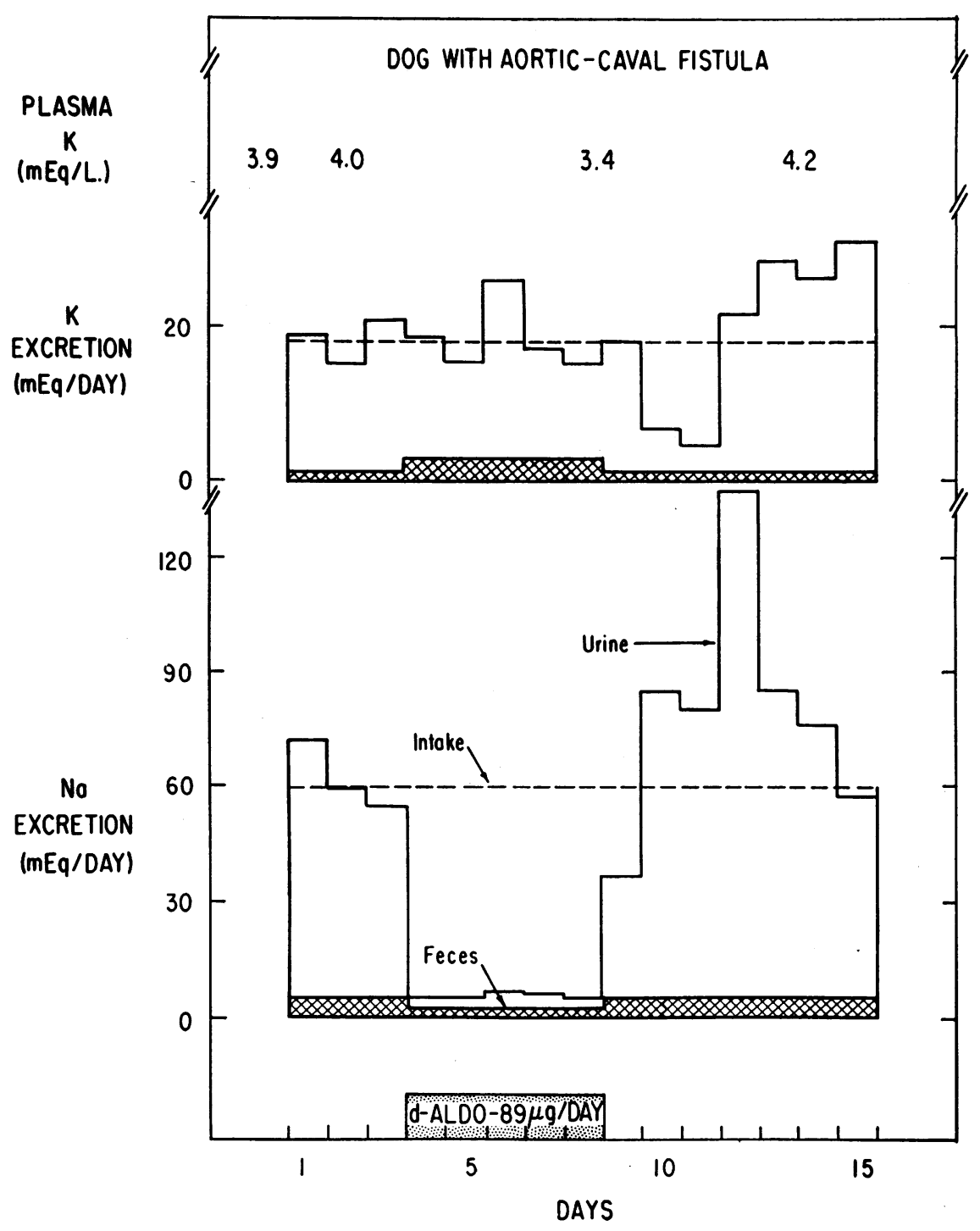

Fig. 4. EFFECtS OF AN IV INFUSion of $d$-ALDOSTERONE ( $89 \mu$ G PER DAY) ON SODIUM and potassium balances and on plasma potassium concentration.

the lowered rates of sodium excretion persisted in the postinfusion period in each experiment. There was no significant increase in body weight during the infusion period, nor did edema form. Increases in urinary potassium excretion occurred uniformly. There was no effect on plasma sodium or potassium concentrations. Fecal sodium and potassium excretion changed in the same direction during angiotensin infusion, and in no instance was the fecal sodium/potassium ratio significantly reduced.

Two of the adrenalectomized animals were later treated with $25 \mathrm{mg}$ DCA daily. Each retained sodium almost completely and formed edema throughout the period of treatment.

Adrenocortical hormone secretion rates during angiotensin infusion. To confirm the apparent adrenocortical mediation of the effects of angiotensin II on sodium excretion, we undertook to measure the effect of angiotensin infusion on the secretion rate of aldosterone in conscious animals with an a-v fistula. Adrenal venous blood was collected through an indwelling adrenolumbar venous catheter on each of 2 days beginning 


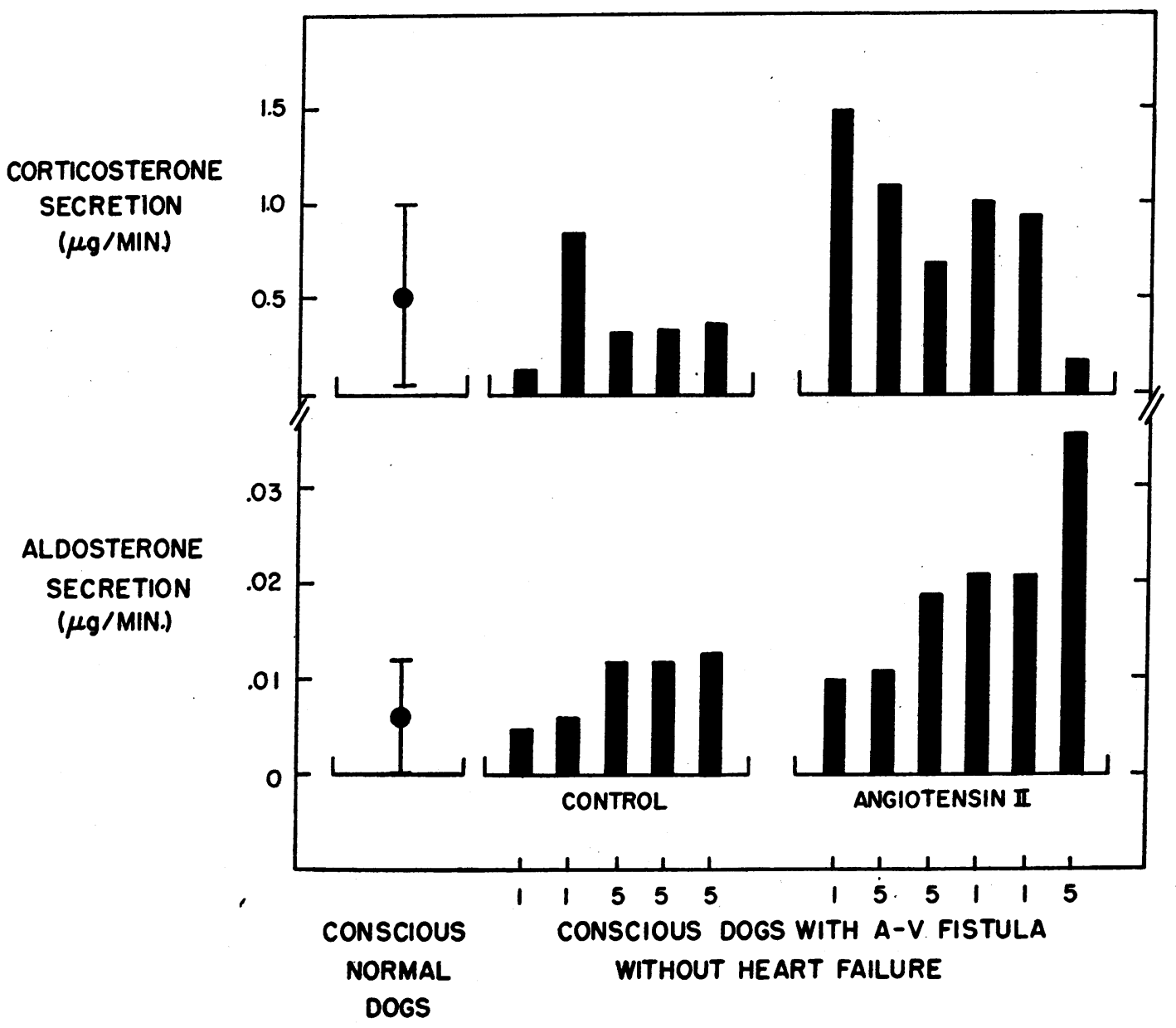

Fig. 5. Simultaneous SECretion Rates OF ALDOSTERone AND OF CORTicosterone in dogs 1 AND 5 Before AND DURING ANGIOTENSIN INFUSION. Each set of values was obtained on a different experimental day and represents the mean of two samples. The arrangement of the data is discussed in the text. For comparison, the average values and standard deviations for steroid secretion in normal, conscious dogs are presented on the left.

with the first day on which sodium balance was approximately restored after laparotomy and catheter placement; angiotensin infusion was then begun, and adrenal venous blood samples were collected daily thereafter as long as adrenal blood flow remained at the level observed during the control period.

This experiment was successful in only two of nine animals. In dogs with an a-v fistula, the veins in the abdominal wall and in the region of the fistula become dilated, tortuous, and fragile, rendering abdominal surgery and placement of an indwelling adrenolumbar vein catheter technically difficult. The postoperative period was frequently complicated by the formation of large hematomata and wound sepsis, which precluded a meaningful experiment.

In the two successfully studied animals, angiotensin infusion was carried out for 3 days. In each animal, aldosterone secretion was approximately doubled during this period. However, in both dogs the lowest aldosterone secretion rates during angiotensin administration occurred on the first day of infusion, and in neither animal was sodium excretion reduced on the first day, in contrast to the results obtained in dogs without the indwelling catheter (Figures 1 and 2, Table I-A). On the succeeding 2 days, however, aldosterone secretion rate increased further in both animals, and sodium retention was nearly complete. 


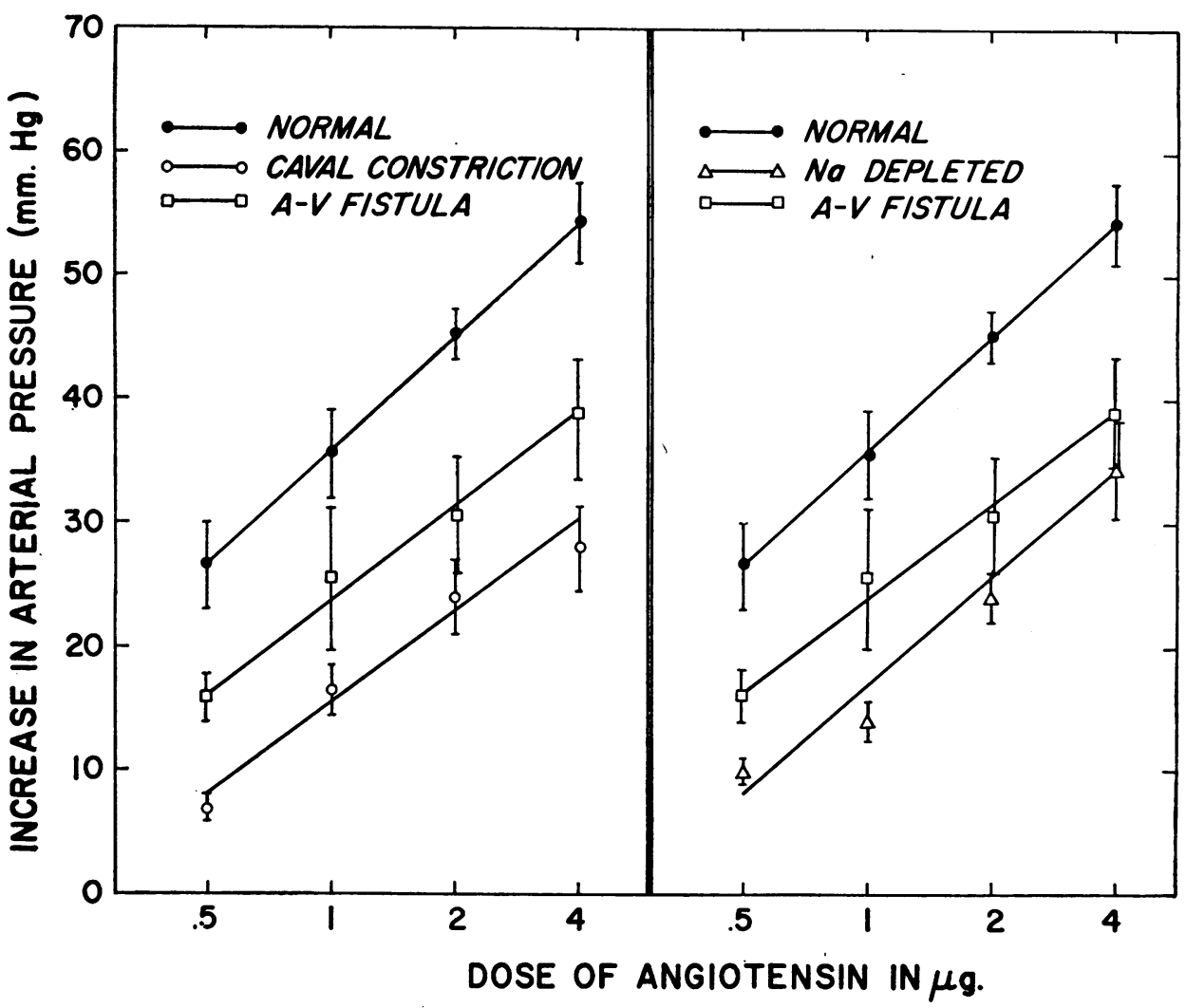

Fig. 6. Curves Relating the dose of angiotensin II AND the PEAK INCREMENT in mean ARTERIAL PRESSURE AFTER AN IV INJECTION OF THE PEPTIDE. The data from dogs with caval constriction and with sodium depletion have been reported previously (13).

In Figure 5, aldosterone secretion rates in the control and the angiotensin infusion periods are plotted in order of progressively increasing magnitude; the simultaneous secretion rates of corticosterone are plotted above. Corticosterone secretion is ordinarily quite variable in conscious animals studied with the Hume-Nelson catheter technique because of spontaneous variation in endogenous ACTH release. During the angiotensin infusion period, the observed adrenocortical secretion rates are the result of stimulation of the gland by exogenous angiotensin superimposed on the variable stimulation by endogenous ACTH. The present results suggest that aldosterone secretion increases in response to angiotensin II in the intact animal in a manner relatively independent of corticosterone secretion.

Arterial and venous pressures during angiotensin II infusion. Table I-A presents the averages of mean arterial pressures that were measured daily during the period of study in each of the dogs with an a-v fistula and intact adrenals. None of the recorded differences in the averages of arterial pressure are statistically significant. Figure 1, which illustrates the individual daily measurements made on $\operatorname{dog} 3$, reveals no discernible pressor action of angiotensin when it was administered at $40 \mu \mathrm{g}$ per $\mathrm{kg}$ per day.

External jugular venous pressures remained at normal levels during angiotensin infusion in all except $\operatorname{dog} 3$, in which the pressure increased by $25 \mathrm{~mm}$ of saline on the sixth day of infusion and by a further $35 \mathrm{~mm}$ on the seventh and last day. After cessation of infusion, venous pressure returned to the normal level; the first measurement in the recovery period was made 24 hours after discontinuing the infusion, and by this time venous pressure had returned to normal.

Similar numerous measurements of arterial and venous pressures were made in the adrenalectomized dogs with an a-v fistula, but no discernible effect of angiotensin was observed with the 
possible exception of a slight increase in arterial pressure in $\operatorname{dog} 2$. The average values for each period of study are presented in Table I-B.

Reduced pressor response of dogs with an a-v fistula to a single injection of angiotensin II. The pressor response of dogs with an a-v fistula to single injections of angiotensin II was significantly reduced below that of normal dogs. Figure 6 illustrates the relationship between the dosage of angiotensin II and the peak increment in mean arterial pressure after injection of the octapeptide in normal animals and in four animals with an a-v fistula. The data in Figure 6 for normal dogs were obtained earlier (13), but in the present study another group of normal animals showed a response almost identical to the earlier findings. The average increments in mean arterial pressure for the four new normal dogs were $25,38,44$, and $52 \mathrm{~mm}$ of $\mathrm{Hg}$ for doses of $0.5,1,2$, and $4 \mu \mathrm{g}$ of angiotensin, respectively. A reduction in pressor response to angiotensin has been reported in dogs with hyperaldosteronism secondary to thoracic caval constriction and to sodium depletion (13), and for comparison those data are also included in Figure 6. The reduction in pressor response to angiotensin II appears to be somewhat greater in the dogs with secondary hyperaldosteronism than in dogs with an a-v fistula but without cardiac failure.

\section{Discussion}

Dogs with an a-v fistula but without cardiac failure reveal no evidence of deranged electrolyte metabolism other than their failure to escape from the sodium-retaining action of electrolyteactive steroids. This occult abnormality does not entail compromise of sodium balance when aldosterone secretion rate is normal; these animals undergo diuresis rapidly after a period of sodium retention induced by angiotensin or exogenous steroid, and they excrete a dietary sodium load as briskly as do normal dogs. GFR, as measured in the postabsorptive state, was reduced below normal in dogs with an a-v fistula (8), but reductions of GFR of similar magnitude produced experimentally by renal arterial constriction in unilaterally nephrectomized dogs did not block the renal escape phenomenon (15). In dogs with an a-v fistula, the postprandial increments in GFR are normal in magnitude, and they coincide with normal increments in sodium excretion to rates in excess of $100 \mu \mathrm{Eq}$ per minute $(5,15)$. During DCA administration to dogs with an $a-v$ fistula (5), the postprandial increase in GFR was indistinguishable from the normal response, whereas renal sodium excretion was markedly reduced. The basis for the abnormally sustained renal response to electrolyte-active steroids in dogs with an a-v fistula or other circulatory lesions is not known, but this phenomenon does not appear to be attributable to impaired renal perfusion or to pre-existing, grossly attenuated renal excretion of sodium.

In the present experiments, angiotensin II simulated the actions of aldosterone on urinary sodium excretion and on the fecal excretion of sodium and potassium. There was no suggestion that these actions of angiotensin were transitory, as reported by Blair-West and his colleagues in sheep (16). There appeared to be some discrepancy between the actions of the electrolyteactive steroids and of angiotensin on plasma potassium concentration. The present data are not sufficient to establish whether this difference is attributable only to different levels of mineralocorticoid activity or whether an additional mechanism is involved. In any event, the lack of effect of angiotensin on plasma potassium concentration corresponds with spontaneous secondary hyperaldosteronism, in which the plasma potassium level is usually unaltered $(8,17)$.

Our data on the effects of angiotensin II in dogs with an a-v fistula and intact adrenals differ strikingly from the response observed in normal dogs (7). With a dose of $20 \mu \mathrm{g}$ per $\mathrm{kg}$ per day of angiotensin in normal animals, sodium retention occurred initially for 1 to 2 days; frequently, transient reductions in sodium excretion occurred later during the infusion of angiotensin. With a dose of $80 \mu \mathrm{g}$ per $\mathrm{kg}$ per day of angiotensin, there was an initial natriuresis, but later in the course of angiotensin infusion transient decreases in sodium excretion were observed.

The average values for sodium excretion in the adrenalectomized dogs with an a-v fistula were lower in the period of angiotensin infusion than in the control period. In the 5-day postinfusion period, average daily renal sodium excretion re- 
mained low in one of the dogs and declined still further in the other two. It is, therefore, not possible to conclude that angiotensin had an effect on renal sodium excretion. If angiotensin had exerted an appreciable effect on sodium excretion, there should have been an increase in sodium excretion during the recovery period. Since the maintenance doses of cortisone acetate and DCA were minimal and possibly inadequate at times, progressive drop in GFR might have occurred. Furthermore, angiotensin could have reduced GFR slightly. Regardless of the mechanism of these relatively small changes in sodium excretion, the most compelling result in the studies of the adrenalectomized dogs is that angiotensin failed to produce complete sodium retention or edema formation, whereas these had been the effects of angiotensin before adrenalectomy.

The results from infusion of angiotensin into the adrenalectomized dogs strongly indicate that the renal action of angiotensin II was mediated by the adrenal cortex. This conclusion is supported by the demonstration of aldosterone hypersecretion during angiotensin infusion and by the unequivocal sodium retention that occurred during an infusion of aldosterone into dog 5 at an average rate (.062 $\mu \mathrm{g}$ per minute), comparable to that at which aldosterone was secreted during angiotensin infusion in the same animal (.035 $\mu \mathrm{g}$ per minute per gland). In this connection it is interesting that a dose of angiotensin of $20 \mu \mathrm{g}$ per $\mathrm{kg}$ per day increased aldosterone excretion in urine in normal dogs (7), and there was no evidence of tachyphylaxis for periods of 5 to 10 days. A tenfold elevation in urinary aldosterone excretion was observed for as long as 5 days with a dose of $80 \mu \mathrm{g}$ per $\mathrm{kg}$ per day of angiotensin in normal dogs (7).

There was no indication in our results of an inhibitory action of angiotensin II on renal tubular reabsorption of sodium, which Laragh and his associates (3) and Vander (4) have reported. Laragh and co-workers gave angiotensin at considerably greater rates than those employed in the present experiments. Vander gave the octapeptide directly into the left renal artery at a rate comparable to our peripheral intravenous rate of infusion of angiotensin and observed inhibition of distal tubular sodium reabsorption in the left kidney, but because of dilution of infused angiotensin by systemic blood, he observed no effect on the right kidney unless the infusion rate was increased three- to fourfold.

The physiological significance of this direct tubular action of angiotensin depends, as Vander has suggested, on whether the concentration of angiotensin II is high in renal capillary plasma, i.e., if there is significant local formation of angiotensin by newly secreted renin. The rates of angiotensin infusion employed in the present study indicate, however, an approximate value for the rate of angiotensin formation in experimental secondary hyperaldosteronism; Vander's results suggest that if angiotensin were formed at this rate predominantly within the kidney, then inhibition of sodium reabsorption would occur. Since quite the opposite occurs in secondary hyperaldosteronism (14), the quantity of angiotensin formed intrarenally is seemingly insufficient to inhibit sodium reabsorption even when renin secretion is high.

When we infused angiotensin at 30 to $47 \mu \mathrm{g}$ per $\mathrm{kg}$ per day, there was no consistent effect on arterial or venous pressure in either dogs with intact adrenals or adrenalectomized dogs with an a-v fistula. In an earlier study of normal dogs (7), $20 \mu \mathrm{g}$ per $\mathrm{kg}$ per day failed to influence blood pressure appreciably. At a rate of infusion of angiotensin II at $80 \mu \mathrm{g}$ per $\mathrm{kg}$ per day, arterial pressure was increased $30 \mathrm{~mm} \mathrm{Hg}$ in one animal but was unchanged in another dog.

Our data on steroid secretion rates in conscious animals with an a-v fistula support the view that angiotensin II can selectively increase the secretion of aldosterone. Similarly, Blair-West and his associates (16) have reported instances during adrenal arterial infusion of angiotensin II in conscious sheep when cortisol and corticosterone secretions fell to minimal values at a time when aldosterone secretion was quite high. Furthermore, observations on conscious dogs with chronic thoracic caval constriction clearly show that very high secretion rates of aldosterone output freqently occur in the presence of low corticosterone and cortisol secretion (18). Certainly angiotensin is capable of stimulating the secretion of adrenocortical steroids other than aldosterone from isolated adrenals, either in vivo (cf. 2) or 
in vitro (19), but in intact animals the feedback inhibition of ACTH release by corticosteroids may act to offset the stimulatory action of angiotensin on corticosterone or cortisol secretion. In this fashion, the negative feedback control of glucocorticoid secretion (cf. 20) may impose a selectivity on the steroidogenic activity of angiotensin II in the intact animal, which cannot occur in isolated adrenals or in hypophysectomized animals.

The reduced sensitivity of dogs with an a-v fistula to the pressor action of single injections of angiotensin II is unexplained. A similar, although greater, reduction in responsiveness to angiotensin has been reported earlier in dogs with hyperaldosteronism and sodium retention secondary to thoracic inferior vena caval constriction or sodium depletion (13). Each of the four dogs with an a-v fistula comprising the present data was in sodium balance at the time of angiotensin injection. The aldosterone secretion rate is normal in such animals with an a-v fistula but without heart failure (21). Our data, therefore, do not support the contention of Bartter, Pronove, Gill, and MacCardle (22) that diminished responsiveness to the pressor effects of angiotensin II serves as a stimulus to renin release and thereby to aldosterone hypersecretion.

In the present chronic experiments, angiotensin II appeared to act like the aldosterone-stimulating hormone, for no fundamental discrepancy was evident between the effects of angiotensin infusion and spontaneous secondary hyperaldosteronism. These findings strengthen the conclusion, already based on a large body of evidence, that it is the renin-angiotensin system which mediates the renal control of aldosterone secretion.

\section{Summary}

Dogs with a large arteriovenous fistula do not escape from the sodium-retaining effect of desoxycorticosterone or aldosterone; these animals were therefore employed to study the effects of angiotensin II in order that the octapeptide's actions which are mediated by aldosterone might be clearly evident. Dogs with a large arteriovenous fistula received a continuous intravenous infusion of angiotensin II for 6 to 11 days. Angiotensin produced virtually complete sodium re- tention, edema formation, and a lowered fecal sodium/potassium ratio but had little or no effect on arterial or venous pressures, potassium balance, or plasma sodium or potassium concentrations. Bilateral adrenalectomy prevented the sodium-retaining action of angiotensin when steroid replacement dosage was held constant. Hypersecretion of aldosterone occurred during angiotensin infusion in each of two dogs in which adrenocortical secretion rates were measured in the conscious state. Angiotensin II mimics the actions of desoxycorticosterone or aldosterone on urinary and fecal sodium excretion and on fecal potassium excretion, although the steroids tend to produce a decreased plasma potassium concentration in dogs with an a-v fistula. In the present experiments angiotensin produced the derangements of electrolyte metabolism that are characteristic of spontaneous secondary hyperaldosteronism.

\section{Acknowledgments}

We are grateful to Dr. Robert Gaunt of Ciba Pharmaceuticals, Summit, N. J., for the synthetic angiotensin II and to Dr. Albert Wettstein of Ciba, Ltd., Basel, Switzerland, for the synthetic aldosterone used for infusion.

\section{References}

1. Urquhart, J. Sodium retention and edema formation during prolonged infusion of angiotensin II into dogs with an arterio-venous fistula. Fed. Proc. 1963, 22, 210.

2. Davis, J. O. The control of aldosterone secretion. Physiologist 1962, 5, 65.

3. Laragh, J. H., P. J. Cannon, C. J. Bentzel, A. M. Sicinski, and J. I. Meltzer. Angiotensin II, norepinephrine, and renal transport of electrolytes and water in normal man and in cirrhosis with ascites. J. clin. Invest. 1963, 42, 1179.

4. Vander, A. J. Inhibition of distal tubular sodium reabsorption by angiotensin II. Amer. J. Physiol. 1963, 205, 133.

5. Davis, J. O., J. E. Holman, C. C. J. Carpenter, J. Urquhart, and J. T. Higgins, Jr. An extraadrenal factor essential for chronic renal sodium retention in presence of increased sodiumretaining hormone. Circulat. Res. 1964, 14, 17.

6. Davis, J. O., and D. S. Howell. Comparative effect of ACTH, cortisone and DCA on renal function, electrolyte excretion and water exchange in normal dogs. Endocrinology 1953, 52, 245. 
7. Urquhart, J., J. O. Davis, and J. T. Higgins, Jr. Effects of prolonged infusion of angiotensin II in normal dogs. Amer. J. Physiol. 1963, 205, 1241.

8. Davis, J. O., J. Urquhart, J. T. Higgins, Jr., E. Rubin, and P. M. Hartroft. Hypersecretion of aldosterone in dogs with a chronic aortic-caval fistula and high output heart failure. Circulat. Res. In press.

9. Rose, S., and J. F. Nelson. A continuous long-term injector. Aust. J. exp. Biol. med. Sci. 1955, 33, 415.

10. Kliman, B., and R. E. Peterson. Double isotope derivative assay of aldosterone in biological extracts. J. biol. Chem. 1960, 235, 1639.

11. Hume, D., and D. H. Nelson. Adrenal cortical function in surgical shock. Surg. Forum 1954, 5, 568.

12. Davis, J. O., A. E. Lindsay, and J. L. Southworth. Mechanisms of fluid and electrolyte retention in experimental preparations in dogs. I. Acute and chronic pericarditis. Bull. Johns Hopk. Hosp. 1952, 90, 64.

13. Davis, J. O., P. M. Hartroft, E. O. Titus, C. C. J. Carpenter, C. R. Ayers, and H. E. Spiegel. The role of the renin-angiotensin system in the control of aldosterone secretion. J. clin. Invest. 1962, 41, 378.

14. Davis, J. O., and D. S. Howell. Mechanisms of fluid and electrolyte retention in experimental preparations in dogs. II. With thoracic inferior vena cava constriction. Circulat. Res. 1953, 1, 171.

15. Urquhart, J., J. O. Davis, and J. T. Higgins, Jr. Independence of GFR and the abnormally sus- tained renal response to the sodium-retaining action of electrolyte-active steroids. Physiologist 1963, 6, 290.

16. Blair-West, J. R., J. P. Coghlan, D. A. Denton, J. R. Goding, J. A. Munro, R. E. Peterson, and M. Wintour. Humoral stimulation of adrenal cortical secretion. J. clin. Invest. 1962, 41, 1606.

17. Davis, J. O., J. Urquhart, and J. T. Higgins, Jr. The effects of alterations of plasma sodium and potassium concentration on aldosterone secretion. J. clin. Invest. 1963, 42, 597.

18. Davis, J. O., C. C. J. Carpenter, C. R. Ayers, and R. C. Bahn. Relation of anterior pituitary function to aldosterone and corticosterone secretion in conscious dogs. Amer. J. Physiol. 1960, 199, 212.

19. Kaplan, N. M., and F. C. Bartter. The effect of ACTH, renin, angiotensin II, and various precursors on biosynthesis of aldosterone by adrenal slices. J. clin. Invest. 1962, 41, 715.

20. Yates, F. E., and J. Urquhart. Control of plasma concentrations of adrenocortical hormones. Physiol. Rev. 1962, 42, 359.

21. Davis, J. O., J. Urquhart, and J. T. Higgins, Jr. Renin, angiotensin and aldosterone in experimental secondary hyperaldosteronism. Canad. med. Ass. J. 1964, 90, 245.

22. Bartter, F. C., P. Pronove, J. R. Gill, Jr., and R. C. MacCardle. Hyperplasia of the juxtaglomerular complex with hyperaldosteronism and hypokalemic alkalosis. A new syndrome. Amer. J. Med. 1962, 33, 811. 